\title{
Erratum to: Abstracts of the 51st Annual Meeting of the EASD, Stockholm 2015. 'Dapagliflozin reduces albuminuria on top of renin-angiotensin system blockade in hypertensive patients with diabetes'
}

\author{
H. J. Lambers Heerspink ${ }^{1}$ - E. Johnsson ${ }^{2}$ - I. Gause-Nilsson ${ }^{2}$ • C. Sjöström ${ }^{2}$
}

Published online: 24 September 2015

(C) Springer-Verlag Berlin Heidelberg 2015

Erratum to: Diabetologia

DOI 10.1007/s00125-015-3687-4

Unfortunately there was a mistake in the title of abstract number 185 presented at the 51st EASD Annual Meeting. The correct title ('hypertensive' rather than 'hypersensitive') is given above. In addition, please note that the correct units for estimated glomerular filtration rate (eGFR) in the table are $\mathrm{ml} \mathrm{min}^{-1} 1.73 \mathrm{~m}^{-2}$ (not $\mathrm{mg} \mathrm{ml}^{-1} 1.73 \mathrm{~m}^{-2}$ ).

2 AstraZeneca, Mölndal, Sweden 